\title{
Participatory Governance through Youth Volunteerism in Public Sector of Pakistan
}

\author{
Kamran Ahmed Soomro (Corresponding author) \\ College of Public Administration, Huazhong University of Science \& Technology \\ Wuhan 430074, Hubei, P.R China \\ E-mail: Kamransoomro@live.com \\ Tan Shukui \\ College of Public Administration, Huazhong University of Science \& Technology \\ Wuhan 430074, Hubei, P.R China
}

Mattiullah Butt

School of Management, Huazhong University of Science \& Technology

Wuhan 430074, Hubei, P.R China

Vivake Anand

School of Economics, Huazhong University of Science \& Technology

Wuhan 430074, Hubei, P.R China

Received: June 10, 2016 Accepted: June 28, 2016 Published: July 10, 2016

doi:10.5296/jpag.v6i2.9722 URL: http://dx.doi.org/10.5296/jpag.v6i2.9722

\begin{abstract}
Participatory governance in public sector is of great importance especially for a democratic country like Pakistan. In this paper we discuss Youth Volunteerism as tool to ensure participation of young people in public service delivery as partners of the government. This research is based on primary data collected on convenience sampling basis, through questionnaires distributed among 243 youth studying in colleges of selected areas of Pakistan. The objective of this research was to find out the perception of young people about Volunteerism in public sector and to find factors that may encourage them to engage in
\end{abstract}


participatory governance through volunteering in public sector institutions of Pakistan. Data was analyzed through SPSS-21, using Multiple Regression Analysis and Pearson's Correlation techniques. The results show that young people in Pakistan are willing to volunteer their services in the public sector because they think it is honor for them, it is need of the time and that it will increase the productivity of the public institutions. This study concludes that promoting culture of volunteerism in the public sector of Pakistan will enable young people to become part of government in service deliver, will reduce public-government gap, will help reduce shortage of workforce in public sector and will increase the productivity of public institutions.

Keywords: Participatory governance, Youth, Volunteerism, Public sector, Pakistan

\section{Introduction}

Participatory governance is a concept gaining much attention by researchers, promoting civic participation in matters of public institutions as an important part of new governance. In the wake of public management and governance issues, Volunteerism in public sector can be a better strategy to engage young people in the execution and delivery of public services in selected areas. It is also research gap to study the magnitude and scope of volunteer works in the public sector. Sirianni (2002) is of the opinion that there is need of expanding community leadership through youth engagement in civic decisions. Nelson (2005) discusses the benefits of volunteerism and argues that youth involvement in civic matters can decrease the drug addiction, crime and incarceration rates. Volunteer activities can do away with class system in the society by establishing contact between unlikely partners and ameliorate social exclusion among people from diverse backgrounds. The fact that public managers concerns complain for lack of the funding and staff to utilize volunteers suggests that governmental capacity poses the main challenge for expanded volunteer involvement in local governments. Engaging young people in social, political and civic matters boosts participatory governance which not only helps government in effective service delivery but also empowers youth (Soomro, K.A. \& Shukui, T., 2015).

Volunteerism is a vast term mostly related to non-profit organizations, but there has been little research conducted to study the role of volunteer activities in the government institutions which may help them in the delivery of public services. Volunteering continues to be a social construct with multiple definitions. It is complex to understand what the word volunteer can mean as it raises some complex issues to be studied, described and analyzed. Different authors (Clary et al., 1998; Finkelstien, 2009; Omoto \& Snyder, 1995; Widjaja, 2010) have defined the word in similar and different ways. Five elements have been considered by most authors i.e. no monetary compensation, non-obligatory action, on-going and planned activity, organizational context and carried out for human helpfulness and betterment of society. According to United Nations definition, people in between 15-24 years of age are considered as youth while others including USAID, assume 10-29 years as Youth. Meanwhile, in this paper, we will follow the Pakistan's official definition which considers people from 15-29 years of age, as Youth (National Youth Policy, 2012). 


\subsection{Objective of the study}

The main objective of this study is to find out the perception of young people about Volunteerism in public sector and to find factors that may encourage them to engage in participatory governance through volunteering in public sector institutions of Pakistan.

\subsection{Hypotheses}

H1: Young people consider it honor to volunteer in public sector institutions

$\mathrm{H} 2$ : Young people are ready to volunteer in public sector institutions because there is more need of such activism in public sector

H3: Volunteerism will increase the productivity of public sector institutions

H4: If Government promotes Volunteerism in public sector, youth will be ready to volunteer their services

\section{Literature Review}

\subsection{Participatory Governance in Public Sector}

Bingham, Nabatchi, and O'Leary (2005) exhort upon the point that civic participation in matters of public institutions is an important part of new governance. Moreover, to better understand new governance, it is not enough to just focus on the tools, but tool users and tool makers, the humans, including public administrators and the citizens, need to be considered as major stakeholders. Brudney (2000) exhorts that the role of citizens in civic affairs must be explained, elaborated and encouraged in order to make them part of policymaking process. For decades nonprofit organizations have been partners to the state for delivery of public services, like health and social services in different countries, with varying nature of contract terms. This has for sure helped governments to cut their costs and cope with their budget constraints. According to Smith (2010) in any way the role of citizens remains pivotal; nonprofit organizations also rely much upon the volunteers and public to execute their programs. Therefore, whenever there is discussion of alliance between government and nonprofit organizations for public management, the role of citizen engagement cannot be ignored. In order to remain useful in new governance era, nonprofit organizations have to invest on volunteer management and leadership development to expand community engagement. Brown (1999) discusses that Volunteers have proved to enhance government productivity by lowering labor costs and simultaneously expanding the scope and the quality of public services. They may also prove to strengthen relationship between public institutions and the community.

Sirianni (2002) is of the opinion that there is need of expanding community leadership through youth engagement in civic decisions. It is important to introduce a change in the system which is possible when we consider young people as asset not deficit for the society. Strong political will and democracy can help create capacity building centers for youth to prepare them for participation in community development programs including volunteer projects. Rotolo (2006) discovered that Public sector employees have higher motivation to 
volunteer as compared to private sector employees. They have different motivation and values while working for the public as their service is not profit oriented; they have interest to work as volunteer in the community services because these volunteer organization indirectly support and complement the services offered by public sector, like education, health etc.; moreover they have good and close relationship with the nonprofit organizations and volunteers, this attachment does motivate public sector employees to volunteer. Soomro K.A, et al. (2015) found that young people are enthusiastic to adopt modern technology in order to interact with government and to be active part of the social, political and civic matters of the country.

\subsection{Volunteerism in Public Sector}

Volunteerism is a vast term mostly related to nonprofit organizations, but there has been little research conducted to study the role of volunteer activities in the government institutions which may help them in the delivery of public service. Brudney (2000) points out that it is important to understand the expected positive role volunteers can play to make a government institution work better. It is also research gap to study the magnitude and scope of volunteer works in the public sector. Public health institutions always need collaborative efforts to provide quality health service to the large population. There we find shortage of funds, doctors, medicines, staff, infrastructure etc. in public hospitals. DeCamp (2011) argues that though promoting volunteerism in public health and public hospitals can help meet many requirements but this is a sensitive area; people are very much concerned about the quality, authenticity and trust. So, when recruiting volunteers, care should be taken to select perfect people for the specific volunteer task. Moreover, community confidence must be achieved through public awareness.

Butt, M., Hu, B., \& Soomro, K. A. (2015) found that young people are more willing to participating in the volunteering activities, but lack of such opportunities creates hurdles. They also found that by rendering volunteer services young people become active citizens and contribute towards society's wellbeing.

Nelson (2005) discussed that Micro elements of National strategy for Volunteerism show us there are seven basic characteristics of a successful policy which include: a working definition of a volunteer, protection of the rights and obligations of volunteers, budgetary support, publicity and information management, incentives, coordination, and training/technical assistance. Safrit (2001) believes that employees' motivation is major challenge in public sector. Keeping in view the civil service protection, job security and no major accountability, it is difficult for managers to fire, punish or reward employees according to their performance. Brooks (2002) found that organizations must encourage their employees to volunteer in the community services in the area where the organization is working. It will not only help organization to understand the people for whom they are working but will also create a good image for organization in the mind of public.

According to Cariño (2008) board of governance in private sector consists of paid senior and expert members while in nonprofit organization, there are experts of different fields serving voluntarily as members of the board. Similarly, such bunch of well-known and expert 
individuals from the community can be made as part of board of governance of the public sector. It will not only add value to the top level strategy making process but will also send positive message and will uplift credibility of the institution in the eyes of public. Edelenbos et al (2010) suggested four types of interfaces between government institutions and interactive governance: political (politicians willing to participate in interactive governance), executive (ministers and local Govt. officials), professional (experts of certain field) and policy (predefined outcomes). These four interfaces help to involve stakeholders in the process of policymaking. Basil (2009) thinks that volunteering of employees can also be an element of the CSR profile of a company, while providing the company's employees with important skills and enrichment of their professional lives. Referring to benefits of volunteerism, Steen (2006) says that promoting volunteerism culture in the public sector can help generate the altruistic traits among employees, leading to much better level of motivation needed to excel in the public institution.

Georgellis (2011) contends that intrinsically or public service motivated employees are attracted to public sector jobs because of a higher satisfaction with the nature of the work itself as the public sector could offer greater opportunities for pro-social or altruistic behaviors. Steen T. (2006) asserts that a potentially fruitful avenue for future research will be to investigate whether workplace characteristics in the public sector influence the level of intrinsic motivation. A main research question will be whether employees who are not inclined to be public service motivated can have their attitudes and beliefs changed by working in the public sector so that they exhibit a higher level of intrinsic motivation. Nelson (2005) discusses the benefits of volunteerism and argues that youth involvement in civic matters can decrease the drug addiction, crime and incarceration rates. Volunteer activities can do away with class system in the society by establishing contact between unlikely partners and ameliorate social exclusion among people from diverse backgrounds. The fact that public managers concerns complain for lack of the funding and staff to utilize volunteers suggests that governmental capacity poses the main challenge for expanded volunteer involvement in local governments.

Brudney (2000) argues that while the supply side of volunteer availability and recruitment is emphasized the demand side is too easily ignored-that is, whether public or private agencies have the infrastructure in place to recruit, train, deploy, supervise and retain greater numbers of volunteers. Mutawa \& Ali, M. (2012) in their research found that with volunteers in the government service delivery process, government institutions have more capability to utilize their available resources and can have cost saving. Moreover their research findings show that volunteer programs in government institutions lead to improved relations with the community.

\subsection{Volunteerism and Government}

Generally the governments and volunteer organizations have the mutual purpose of working for the betterment of society. Whereas government is involved in making improvements in living standards at national, provincial and city levels, the Volunteer organizations are often involvement in working for the betterment of society and humanity in one or more societies. 
Instead of competing with the volunteer social organizations, the governments often get involved with them and support them financially or otherwise for expansion and improvement in their operations. Different Governments have acknowledged the importance of volunteering for example Thatcher's ideals of "activate citizens" and rolling back the frontiers of the state in the United Kingdom (Billis \& Harris, 1992) and announcement of President George W. Bush (on January 29th, 2001) for the creation of white house office for religious-based and community groups ("Bush on the creation of a White House Office," 2001). The year 2001 was declared the International Year of the Volunteer by the UN to encourage more governments to focus on volunteering activities (Butcher, 2011).

\subsection{Benefits of Volunteerism in Public Sector}

According to Brudney (1993) Participatory governance through volunteerism can have positive impacts upon productivity of service delivery by the government institutions. Volunteerism in public sector reduces the cost of service delivery, leads to expansion of capability by assisting the current employees and encouraging introduction of new programs, contributes to the better service quality with the help of skilled volunteers and creates positive image in the community through extended interaction and communication of volunteers with public. Brudney (2000) argues that in almost all the public sector institutions there are employee unions. Such employee unions have support of employees and they enjoy special protocol and support from the heads of the institutions due to their political influence and employees support. These unions pose multiple challenges to the concept of promoting volunteerism in the government institutions mainly because the volunteers, the outsiders, may disturb their privacy, may prove to be watchdog or may even snatch their employment related opportunities. Brudney (1993) thinks that such preoccupied assumptions and fears among the employee unions lead them to oppose the participation of public in the governance of public sector. When we discuss about the advantages of volunteerism in government services, we also encounter disadvantages in the shape of challenges posed by threatened public employees' unions, government employees, managers, lack of ability to recruit, manage and retain volunteer employees etc.

\section{Methodology}

For Collection of data for the study, convenience sampling technique was used and questionnaires were distributed to be filled up by young people (students of colleges) in selected areas of Sindh and Punjab province of Pakistan. Total of 243 responses were finalized for this research. The data was then empirically tested with the help of software SPSS-21 version. Multiple regression analysis was used to find out impact of independent variables upon the dependent variable, and correlation analysis was conducted to prove the hypotheses. The questionnaire consisted of likert scale, 1 showing the extreme disagreement and 7 meant extreme agreement.

\section{Results Analysis and Findings}

\subsection{Demographics}

243 responses were sorted and analyzed, with $69.5 \%$ male and $30.5 \%$ female respondents. As 


\section{Al Macrothink}

the target audience for this research was youth, so the $95.9 \%$ of the participants are aged below 30 years. Out of total population $73.3 \%$ of the respondents were students and $23.9 \%$ were employees, while only $2.9 \%$ were self-employed.

\subsection{Multiple Regression Analysis}

In order to find out the contribution of each independent variables in explaining the dependent variable (willingness to volunteer in public sector), multiple regression analysis was used. The preliminary tests were conducted to check the multi-linearity of the variables used in the regression.

The independent variables show normal co-linearity statistics, for example, $\beta 1=$ $($ Tolerance $=.910, \mathrm{VIF}=1.099), \beta 2=($ Tolerance $=.833, \mathrm{VIF}=1.200) \beta 3=($ Tolerance $=.669$, $\mathrm{VIF}=1.494) \beta 4=($ Tolerance $=.780, \mathrm{VIF}=1.282)$.

The overall model results show that $\mathrm{R}$ value is $.467, \mathrm{R}$ square is .218 and Adjusted $\mathrm{R}$ square value is .208.

The regression equation and variables are given below:

$\mathrm{Y}=\beta 0+\beta 1 \mathrm{X} 1+\beta 2 \mathrm{X} 2+\beta 3 \mathrm{X3}+\beta 4 \mathrm{X} 4+\mathrm{e}$

$\mathrm{Y}=$ Willingness to volunteer in Public Sector

$\mathrm{X} 1=$ Honor to volunteer in Public Sector

$\mathrm{X} 2=$ Need of Volunteerism in Public Sector

$\mathrm{X} 3$ = Productivity will be increase with volunteerism

$\mathrm{X} 4=$ Government promotes Volunteerism in Public Sector

The results of multiple regression shows that all the independent variables have positive impact upon the dependent variable. $\beta 1$ is highly significant with value of $.382, \beta 2$ is significant with value of $.276, \beta 3$ is highly significant with value of .222 , and $\beta 4$ is also highly significant with value of .095. (See table 1). 
Table 1 Multiple Regression Model

\section{Coefficients}

\begin{tabular}{|c|c|c|c|c|c|}
\hline \multirow[t]{2}{*}{ Model } & & \multicolumn{2}{|c|}{$\begin{array}{l}\text { Unstandardized } \\
\text { Coefficients }\end{array}$} & \multirow[t]{2}{*}{$\mathrm{t}$} & \multirow[t]{2}{*}{ Sig. } \\
\hline & & $\mathrm{B}$ & Std. Error & & \\
\hline & $\beta_{\mathrm{o}}($ Constant $)$ & 1.272 & .400 & 3.176 & $.002 * *$ \\
\hline & $\beta_{1}$ Honor to volunteer & .382 & .062 & 6.144 & $.000 * *$ \\
\hline & $\beta_{2}$ Need to volunteer & .276 & .064 & 3.102 & $.059 *$ \\
\hline & $\beta_{3} \quad$ Productivity & .222 & .070 & 3.153 & $.002 * *$ \\
\hline & $\begin{array}{ll}\beta_{4} & \text { Vol: } \\
\text { Opportunities } & \end{array}$ & .095 & .065 & 1.466 & $.044^{* *}$ \\
\hline
\end{tabular}

a. Dependent Variable: Willingness to volunteer in Public Sector

$* p<.05$ Significant

** $p<.01$ Highly Significant

\subsection{Results corresponding to the hypotheses}

H1: Young people consider it honor to volunteer in public sector institutions

The relationship between perceived 'feeling of honour' and 'willingness to volunteer in Public Sector' was investigated by using Pearson product-moment correlation coefficient. There was a strong, positive correlation between the two variables, $r=.424, n=243, p<.001$, with high levels of perceived 'feeling of honour' associated with higher levels of 'willingness to volunteer in Public Sector'. (See table 2). Moreover, in multiple regression, the $\beta 1$ is highly significant with value of .382, which supports this hypothesis.

H2: Young people are ready to volunteer in public sector institutions because there is more need of such activism in public sector

The relationship between 'the feeling that there is need of volunteerism in Public Sector' and 'willingness to volunteer in Public Sector' was explored by using Pearson product-moment correlation coefficient. There was a strong positive correlation between the two variables, $\mathrm{r}=.159, \mathrm{n}=243, \mathrm{p}<.005$, which shows that the youth who feel there is need of introducing 
volunteerism culture in public sector will be more willing to volunteer their services. (See table 2). Moreover, in multiple regression, $\beta 2$ is significant with value of .276 , which supports this hypothesis.

H3: Youth activism through Volunteerism will increase the productivity of public sector institutions

The relationship between 'Expectation for increased productivity' and 'willingness to volunteer in Public Sector' was investigated by using Pearson product-moment correlation coefficient. There was a strong, positive correlation between the two variables, $\mathrm{r}=.305, \mathrm{n}=$ $243, \mathrm{p}<.001$, which indicates higher positive relationship between the two variables. (See table 2). Moreover, in multiple regression, $\beta 3$ is highly significant with value of .222, supporting this hypothesis.

H4: If Government promotes Volunteerism in public sector, youth will be ready to volunteer their services

The association between 'Perception about Government promoting Volunteerism in PS' and 'Willingness to volunteer in Public Sector' was analyzed by using Pearson product-moment correlation coefficient. There was a strong positive correlation between the two variables, $\mathrm{r}=.198, \mathrm{n}=243, \mathrm{p}<.001$, which shows that the young respondents who feel government promotes volunteerism culture in public sector will be more willing to volunteer their services. (See table 2). And as per results of multiple regression $\beta 4$ is also highly significant with value of .095 , it also supports this hypothesis.

Table 2 Pearson Product-moment Correlations

\begin{tabular}{|c|c|c|c|c|c|}
\hline Scale & 1 & 2 & 3 & 4 & 5 \\
\hline $\begin{array}{l}\text { 1. Willingness to volunteer in } \\
\text { Public Sector }\end{array}$ & ----- & $.424^{* *}$ & $.305^{* *}$ & $.159^{*}$ & $.198^{* *}$ \\
\hline $\begin{array}{l}\text { 2. It is honour to volunteer in } \\
\text { Public Sector }\end{array}$ & & ----- & $.276^{* * *}$ & $.202^{* *}$ & .082 \\
\hline $\begin{array}{l}\text { 3. Will increase the } \\
\text { productivity of PS }\end{array}$ & & & ----- & $.390^{* *}$ & $.461^{\text {** }}$ \\
\hline 4. Need of volunteerism in PS & & & & ----- & $.241^{* *}$ \\
\hline $\begin{array}{l}\text { 5. Government promotes } \\
\text { Volunteerism in PS }\end{array}$ & & & & & ----- \\
\hline
\end{tabular}




\section{Discussion}

This study empirically found that young people with high level of perceived 'feeling of honour' show higher level of 'willingness to volunteer in Public Sector', $(r=.424, n=243, p$ $<.001),\left(\beta 1=.382^{* *}\right)$. It also found that the youth who feel that there is need of introducing volunteerism culture in public sector will be more willing to volunteer their services, $(r=.159$, $\mathrm{n}=243, \mathrm{p}<.005),\left(\beta 2=.276^{*}\right.$.) The relationship between 'Expectation for increased productivity' and 'willingness to volunteer in Public Sector' was found strong with positive correlation between the two variables, $(\mathrm{r}=.305, \mathrm{n}=243, \mathrm{p}<.001)$ and significant positive coefficient value $\left(\beta 3=.222^{* *}\right)$. The results show that the young respondents who feel government promotes volunteerism culture in public sector will be more willing to volunteer their services. There was a strong positive correlation between the two variables $(\mathrm{r}=.198, \mathrm{n}=$ $243, \mathrm{p}<.001)$ and significant positive coefficient value $\left(\beta 4=.095^{* *}\right)$. Moreover, the findings show that young people in Pakistan are willing to volunteer their services in the public sector because they think it is honor for them and it will increase the productivity of the public institutions. This study also concludes that young people are energetic and enthusiastic to become part of any government organization as volunteers, like in education, health and municipality services, but due to lack of such opportunities they stay away from such activities. Therefore, this study concludes that promoting culture of volunteerism in the public sector of Pakistan will enable young people to be part of system and will enable them to work for the betterment of society. Meanwhile, it will also meet the gap and shortage of workforce in public sector.

\section{Conclusion}

In this paper we studied Youth Volunteerism as tool to ensure participation of young people as partners in public service delivery. The objective of this research was to find out the perception of young people about Volunteerism in public sector and to find factors that may encourage them to engage in participatory governance through volunteering in public sector institutions of Pakistan. Data was analyzed through SPSS-21, by using Multiple Regression Analysis and Pearson's Correlation techniques; the results show that young people in Pakistan are willing to volunteer their services in the public sector because they think it is honor for them, it is need of the time and that it will increase the productivity of the public institutions. This study concludes that promoting culture of volunteerism in the public sector of Pakistan will enable young people to become part of government in service deliver, will reduce public-government gap, will help reduce shortage of workforce in public sector and will increase the productivity of public institutions. This paper puts forward an idea of encouraging volunteerism in government institutions of Pakistan; while at present most of such volunteering activities are prevalent in non-government sector. This paper asserts that by inculcating this culture of youth volunteerism especially in government institution of great importance for masses, like education, health, and municipality matters will have multitude of diverse benefits for all stakeholders including government, youth and society. This paper has certain limitations, as it is based on small sample size; data was collected only from college students of two provinces of the country and mostly the perception of young people is studied. Moreover, this paper puts forward future research directions, for example, further 
research can be carried out to find out the government's perspective of introducing volunteerism in public institutions, individual case studies can be conducted to find out the need and impact of volunteerism in particular government institution and detailed strategies can be suggested to encourage and compensate the volunteers recruited to work in public institutions.

\section{References}

Basil, D. Z., Runte, M. S., Easwaramoorthy, M., \& Barr, C. (2009). Company support for employee volunteering: A national survey of companies in Canada. Journal of Business Ethics, 85(2), 387-398. behavioral change. Psychological Review, 84(2), 191-215.

Billis, D., \& Harris, M. (1992). Taking the strain of change: UK local and voluntary organisations enter the post-Thatcher period. Nonprofit and Voluntary Sector Quarterly, 21, 211-226.

Bingham, L. B., Nabatchi, T., \& O'Leary, R. (2005). The new governance: Practices and processes for stakeholder and citizen participation in the work of government. Public Administration Review, 65(5), 547-558.

Brooks, A. C. (2002). Can Nonprofit Management Help Answer Public Management's "Big Questions"? Public Administration Review, 62(3), 259-266.

Brown, E. (1999). The Scope of Volunteer Activity and Public Service (Vol. 62).

Brudney, J. L. (1993). Volunteer involvement in the delivery of public services: Advantages and disadvantages. Public Productivity \& Management Review, 283-297.

Brudney, J. L., \& Kellough, J. E. (2000). Volunteers in state government: Involvement, management, and benefits. Nonprofit and Voluntary Sector Quarterly, 29(1), 111-130.

Bush on the creation of a White House Office. (2001). New York Times. Retrieved October 15 , 2014 , from http://www.nytimes.com/2001/01/30/us/bush-on-the-creation-of-a-white-house-office-tied-toreligion.html

Butcher, J. (2011). Volunteering in Developing Countries. In R. Taylor (Ed.), Third Sector Research (pp. 91-103). New York, NY: Springer New York. doi:10.1007/978-1-4419-5707-8

Butt, M., Hu, B., \& Soomro, K. A. (2015). Volunteering Activities in Developing Countries: A Study of Youth Participation in Pakistan. European Journal of Business and Management, 7(13), 317-326.

Cariño, L. V. (2008). Collective Governance: An Alternative Model of Third Sector Governance Comparative Third Sector Governance in Asia (pp. 131-150): Springer.

DeCamp, M. (2011). Ethical review of global short-term medical volunteerism. Paper presented at the HEC forum. 


\section{Macrothink}

Journal of Public Administration and Governance

ISSN 2161-7104

2016, Vol. 6, No. 2

Edelenbos, J., van Schie, N., \& Gerrits, L. (2010). Organizing interfaces between government institutions and interactive governance. Policy Sciences, 43(1), 73-94.

Georgellis, Y., Iossa, E., \& Tabvuma, V. (2011). Crowding out intrinsic motivation in the public sector. Journal of Public Administration Research and Theory, 21(3), 473-493.

Mutawa, O. S. A.-, \& Ali, M. (2012). Impact of Volunteer Management Practice on Volunteer Motivation and Satisfaction to Enhance Volunteer Retention. World Journal of Social Sciences, 2(6), 25-38.

National Youth Policy (2009), National Youth Policy-2009, retrieved from Ministry of youth affairs, Government of Pakistan, Islamabad.

Nelson, T. (2005). A comparative look at national volunteerism legislation. The Inter-American Initiative for Social Capital, Ethics and Development, Inter-American Development Bank.

Rotolo, T., \& Wilson, J. (2006). Employment sector and volunteering: The contribution of nonprofit and public sector workers to the volunteer labor force. The Sociological Quarterly, 47(1), 21-40.

Safrit, R. D., \& Lopez, J. (2001). Exploring Hispanic American involvement in community leadership through volunteerism. Journal of Leadership \& Organizational Studies, 7(4), 3-19.

Smith, S. R. (2010). Nonprofits and public administration reconciling performance management and citizen engagement. The American Review of Public Administration, 40(2), 129-152.

Soomro, K.A. \& Shukui, T. (2015). Youth Development Challenges in Pakistan: Need for Youth Empowerment. Public Policy and Administration Research, Vol.5, No.11, 2015

Soomro, K.A., Shukui, T., \& Shaikh S.A, (2015). Factors Motivating Youth for the Adoption of e-Government Services in Pakistan,. Asian Journal of Social Sciences \& Humanities Vol. $4(4)$.

Steen, T. (2006). Public sector motivation: Is there something to learn from the study of volunteerism? Public Policy and Administration, 21(1), 49-62.

\section{Copyright Disclaimer}

Copyright for this article is retained by the author(s), with first publication rights granted to the journal.

This is an open-access article distributed under the terms and conditions of the Creative Commons Attribution license (http://creativecommons.org/licenses/by/3.0/). 